\title{
Reproductive Rights Knowledge, Health Care Utilization, and Contraceptive Use in Pakistan: A Reproductive Rights Perspective
}

\author{
Sadia Saeed' \\ Vijayan Pillai iD ${ }^{2}$ \\ Azka Gouher 3 \\ 'Department of Sociology, Quaid-i-Azam \\ University, Islamabad, Pakistan; ${ }^{2}$ School of \\ Social Work, University of Texas at \\ Arlington, Arlington, TX, 760I5, USA; \\ ${ }^{3}$ Truth linternational, Islamabad, Pakistan
}

Introduction: This study investigates the effects of utilization of health care and the level of reproductive rights knowledge on contraceptive use. Current family planning programs in developing countries utilize a two-pronged strategy involving improvement of level of reproductive rights and, right to access health care systems. The effectiveness of this strategy in developing countries such as Pakistan remains poorly investigated. This study aimed at examining the effect of reproductive rights knowledge on contraceptive use.

Methods: The target population is educated, 18- to 45-year-old married Pakistani women. The sample is composed of 160 nonrandomly selected purposive group of women. We gathered data using a structured questionnaire and analyzed the data using several multivariate methods such as latent class analysis and multiple classification analysis.

Results: Our results suggest that reproductive rights knowledge has no direct effect on contraceptive use. Furthermore, the level of utilization of the health care system plays a significant intervening role between reproductive rights knowledge and contraceptive use. Discussion: Our results call for improving access and availability of health care while strengthening the awareness and knowledge of reproductive rights among women to improve their capacity to utilize family planning methods. Public awareness and educational programs are indeed necessary to promote knowledge of reproductive rights among women in developing countries. As public health campaigns propagandize the crucial role reproductive rights play in improving women's reproductive health, it is important to maintain a structurally harmonious relationship between health care systems and family planning programs promoting contraceptive use. This approach is more likely to result in significant returns for public awareness campaigns promoting reproductive rights in developing countries.

Keywords: reproductive health, women's rights, multiple classification analysis, Pakistan

\section{Introduction}

Modern family planning has long been an influential component of demographic transition. ${ }^{1}$ Driven by fears of catastrophic human consequences of population growth, most governments in developing countries promoted family planning programs to hasten the pace of fertility decline. ${ }^{2}$ Consequently, successful family planning programs in developing countries have focused on improving the availability and accessibility of modern methods of contraception such as male condoms, pills, and injectables in their campaign to reduce population growth. ${ }^{2}$
Correspondence: Vijayan Pillai

School of Social Work, University of

Texas at Arlington, 2II South Cooper

Street, Arlington, TX, 76019, USA

Tel + I $81768 \mid 3784$

Email Pillai@uta.edu 
Intense focus on modern contraceptive methods as a tool to hasten the tempo of fertility decline led to human rights violations. ${ }^{3}$ Reports of human rights violations associated with family planning resulted in criticisms at the International Conference on Population and Development at Cairo in 1994 and the Fourth World Conference on Women in Beijing in 1995. The emphasis on reproductive rights as an important value premise and requirement of all family planning programs resulted in the development of reproductive rights approaches toward reproductive health, including sexual health. Improvements in knowledge of reproductive rights is believed to increase utilization of contraception as well as services with respect to birth planning.

Underlying the contemporary attempts to embed traditional population control programs with reproductive rights viewpoints are two strategies: 1) improve the level of reproductive rights knowledge and 2) improve the right to access health care systems. ${ }^{4}$ In spite of the current emphasis on reproductive rights in family planning policies in developing countries, there has been very little effort to educate women of reproductive rights values. Consequently, studies on the impact of reproductive rights knowledge on contraceptive use among women in developing are few and far between.

The purpose of this study is to investigate the effects of two selected determinants: "utilization of health care systems", and level of "reproductive rights knowledge" on "contraceptive use". More specifically, we seek to identify the direct and indirect effects of reproductive rights knowledge levels and utilization of health care systems on contraceptive use in developing countries such as Pakistan. Pakistan offers a useful setting with low levels of contraceptive use and poor utilization of health care systems among women. There are very few studies, if any, on reproductive rights knowledge among Pakistani women.

The definition of women's reproductive rights adopted at the 1995 Beijing World Conference on Women endorses a woman's 1) freedom to decide how many children to have and when to have them, 2) the right to have the information and means to regulate her fertility, and 3) the right to have control over her own body. The Convention on the Elimination of All Forms of Discrimination against Women (CEDAW) is one of the most comprehensive international legal instruments of its kind to define women's rights. The World Health Organization ${ }^{6}$ defined reproductive rights as a basic right of all couples and individuals to decide freely and responsibly the number, spacing, and timing of their children and to have the information and means to do so, and the right to attain the highest standard of sexual and reproductive health.

Central to the concept of reproductive rights is that reproductive rights are human rights and that all women by being human shall enjoy these rights equally. ${ }^{7,8}$. Reproductive rights are conceptualized and promoted as individual rights. Furthermore, it is assumed that women recognize these rights as self-evident and would therefore have knowledge of reproductive rights, even though there may be wide variations in the level of reproductive rights knowledge. ${ }^{9}$ The effect of this variation in knowledge on contraceptive use has not been adequately investigated, even though it is well known that the level of reproductive rights knowledge may influence women's willingness and ability to access health care. ${ }^{10}$

Regardless of community opinions or religious sentiments against individual reproductive rights, from a human rights perspective, women reserve the right to seek and access needed resources (material and nonmaterial) to improve their reproductive health. The ability to use reproductive rights knowledge in making reproductive health decisions expands women's choices and opportunities to seek needed health care. Studies have also found that antenatal care utilization is significantly associated with subsequent contraceptive use among Pakistani women. ${ }^{11}$ This finding underscores the importance of a vigorous health care system necessary to encourage contraceptive use. Improving reproductive rights knowledge among women in reproductive age groups is likely to advance health care utilization resulting in significant increase in contraceptive use rates. We argue that there is a positive and significant association between the level of reproductive rights knowledge and the level of utilization of health care.

Several theories such as the health belief model and the theory of reasoned action suggest that women take into consideration the pros and cons of contraceptive use. ${ }^{12,13}$ These social psychological theories suggest that the likelihood of contraceptive use depends on perceived subjective utilities of the outcomes of contraception. In this regard, Luker's theory of contraceptive risk is very relevant. Kristin Luker argues that when subjective utilities associated with contraceptive use are high while the subjective utilities assigned to pregnancy are low, women are most likely to exercise their right to contraceptive use. ${ }^{14,15}$ The experiences of constraints and barriers to access and utilization of health care are likely to lower subjective 
utilities of contraceptive use. ${ }^{15,16}$ With increased inability to access and utilize health care systems, they are more likely to employ their right to use contraceptives to prevent unplanned births.

Social justice and human rights-based theories such as the capability theory also provide a theoretical frame to identify the direct effects of socio-cultural and economic determinants on contraceptive use. Sen ${ }^{17}$ argues that reproductive rights as an entitlement enable women to access and utilize reproductive health care. However, when such entitlements fail to provide access to health care, and reproductive health care in particular, women are likely to suffer from both shortterm and long-term health setbacks. ${ }^{18}$ One consequence of such obstacles is that it compromises women's capacity to reach adequate levels of functioning to effectively plan for their future health care needs as well. ${ }^{19}$ When health care services are either inadequate or unsatisfactory for women, they are likely to experience deprivation of their capacities to function adequately and plan for their reproductive health wellbeing. ${ }^{16,19,20}$ As women assess their subjective abilities related to contraception, barriers to access, and unsatisfactory experiences within health care systems, they are more likely to be discouraged from exercising their right to use contraception. Such capacity deprivations, according to Sen, ${ }^{17}$ will likely reduce women's ability to plan for their reproductive well-being, including the use of contraception. In sum, social psychological theories as well as the capability theories indicate that as women's level of utilization of health care decreases, the likelihood of contraceptive use declines. ${ }^{21}$

There is extensive literature documenting the effects of demographic variables on contraceptive use. The type of family, ${ }^{22-24}$ working status, ${ }^{25,26}$ and level of education ${ }^{27-29}$ are significantly associated with contraceptive use.

Based on the proposed theory, we hypothesize that

1. As reproductive rights knowledge increases, women are more likely to exercise their right to utilize health care services.

2. As utilization of health care increases, women are more likely to exercise their right to use contraceptives.

3. The effect of reproductive rights knowledge on contraceptive use is indirect and through utilization of health care, the intervening variable.

\section{Materials and Methods}

The research study was conducted in Islamabad, the capital of Pakistan. Five inclusion criteria were used to identify the survey population. The members of population were female, in the reproductive age group 18-45 years, with at least a graduate degree, and held a social position in a formal organization such as colleges and universities, and resided in Islamabad, Pakistan. ${ }^{30}$ There is an extensive literature which suggests that educated women are more likely to adopt new technologies such as modern contraceptives and lifestyles which in due course diffuse to the new cohorts of women. ${ }^{31,32}$ We characterize our target population as an innovative group. Focus on this target population provides us an opportunity to explore the impact of reproductive rights knowledge on contraceptive use in an innovative group.

It was determined that it was feasible to initially contact 200 respondents within available time and manpower resources. Members of our study sample were selected using a referral/snowball technique implemented initially at Quaid-i-Azam University (QAU) Islamabad, Pakistan. Arrangements were made to interview members who were referred to us during the snowball sampling process belonging to educational institutions other than QAU. These respondents were mostly interviewed at a pre-arranged meeting place within QAU. A structured research questionnaire developed by the first and third authors of this study was administered in person. A total of 160 questinnaires were completed at the end of our survey. This accounts for an eighty percent response rate approximately. The following questions were used to measure the three dimensions: reproductive rights knowledge, utilization of health care, and contraceptive use. Participants were asked to respond yes or no to all the questions measuring the three dimensions. The following questions were used to measure contraceptive use. 1) Did you get to decide on the use of contraceptives to avoid pregnancy? 2) Did you know you have the right to family planning? 3) Did you know you have the right to have contraception information and services? 4) Have you ever used contraception to avoid pregnancy? And finally, 5) Have you ever received contraception information and services?

The following questions were used to measure utilization of health care. Most of these questions were designed to address aspects of reproductive health care services provided by health care systems to women in Pakistan. 1) Have you ever sought, received or imparted information related to sexuality? 2) Have you ever received sexuality education? 3) Do you have a say in refraining from having sexual intercourse if you do not want to have it, without getting intimidated by your partner? 4) Have you ever decided either to $b$ sexually active or not? 5) Were your marriage and sexual relation consensual? 6) Did you decide for yourself whether 
to have children or not? 7) Were you ever informed or taken consent regarding medical interventions related to your reproductive processes? 8) Have you ever yourself decided the spacing of children you wanted to have? 9) Have you ever yourself decided the number of children you wanted to have? 10) Have you ever acquired infertility treatment or taken preventive measures against sexually transmitted diseases?

Questions to measure reproductive rights knowledge were as follows: 1) Did you know you have the right to seek, receive, and impart information related to sexuality? 2) Did you know you have the right to receive antenatal care from the doctor? 3) Did you know you have the right to access modern reproductive technology? 4) Did you know you have the right to receive sexual education? 5) Did you know you have the right to have respect for bodily integrity? 6) Did you know you have the right to decide to be sexually active or not? 7) Did you know you have the right to have consensual marriage and form consensual sexual relations? 8) Did you know you have the right to decide whether or not to have children? 9) Do you consider the right to abortion as a reproductive right at all? 10) Did you know you have the right to have informed consent regarding medical interventions? And finally, 11) Did you know you have the right to acquire treatment of infertility and take preventive measures against sexually transmitted diseases?

The three control variables, family type (famtype), working status (workdum) and educational status in terms of graduate degree or higher (edudum) are all dummy variables coded 1 for yes and 0 for no.

We used latent class analysis to obtain a scale to measure the three constructs in this study: reproductive rights knowledge, health care utilization, and contraceptive use. Latent class analysis is particularly suitable for investigating dimensionality under the assumption that there exist latent classes indicated by the selected categorical variables. The estimation of the number of dimensions (classes) underlying the trait was initiated by assuming a two-class model as a good fit. Four categorical variables indicated "contraceptive use" in which larger values indicated higher levels of the latent trait. Those who had high levels of contraceptive use are grouped in one class and the rest in the other. Regarding the number of classes, we used the Vuong-Lo-MendellRubin test $(\mathrm{VLMR}=57.541 ; p<0.001)$ and the bootstrapped parametric likelihood ratio test $(\mathrm{BPLR}=59.545 ; p<$ 0.0001). ${ }^{33}$ To further assess the robustness of the model, we tested for the presence of a three-class structure. The VLMR test and the BPLR test were not statistically significant, which indicates that two classes were more appropriate to identify the class structure of the "contraceptive use" dimension. The probability of belonging to the high "contraceptive use" class was used to measure this dimension.

Ten categorical variables were selected to identify the "utilization of health care" dimension. The evaluation of the number of associated dimensions (classes) was originated by assuming a two-class model as a good fit. Those who had high levels of "utilization of health care" were grouped into a homogenous category and the rest in the other. To identify the number of classes we used both the VLMR and BPLR tests. The Vuong-Lo-Mendell-Rubin test (VLMR = 119.854; $p<0.001)$ and the bootstrapped parametric likelihood ratio test $(\mathrm{BPLR}=120.584 ; p<0.001)$ rejected the null hypothesis that one class is more appropriate than two. To further assess the robustness of the model, we tested for the presence of a threeclass structure. The VLMR test and the BPLR test were not statistically significant, which indicates that two classes were more appropriate to identify the class structure of the "utilization of health care systems" dimension. The probability of belonging to the high "utilization of health care systems" was used to measure this dimension.

Eleven categorical variables were selected to identify the reproductive rights knowledge dimension. The evaluation of the number of associated dimensions (classes) was initiated by assuming a two-class model as a good fit. Those who had high levels of reproductive rights knowledge were assigned to one group and the rest to the other. To identify the number of classes we used both the VLMR and BPLR tests. The Vuong-Lo-Mendell-Rubin test $(\mathrm{VLMR}=489.015, p<0.001)$ and the bootstrapped parametric likelihood ratio test $(\mathrm{BPLR}=490.215 ; p<0.001)$ rejected the null hypothesis that one class is more appropriate than two. To further assess the robustness of the model, we tested for the presence of a three-class structure. The VLMR test and the BPLR test were not statistically significant, which indicates that two classes were more appropriate to identify the class structure of the reproductive rights knowledge dimension. The probability of belonging to the high reproductive rights knowledge class was used to measure this dimension.

The analysis to test our proposed hypotheses was evaluated using two statistical techniques: multiple classification analysis, and path analysis. Multiple classification analysis (MCA) is well suited to test the proposed hypotheses with dependent and independent variables measured at various levels of measurement in this study. The dependent variable, contraceptive use as well as the two main independent variables are measured at interval level with 
the control variables at the nominal level. MCA is robust against violations of linearity assumptions underlying linear regression modeling approaches. Furthermore, the MCA approach includes readily readable presentation formats of results. The coefficients associated with the categories of any selected independent variable in MCA is partitioned in such a way that the response value is the sum of the coefficients of all the categories of the independent variable, grand mean of the outcome variable in question, and random error.

To further explore the relationship between "reproductive rights knowledge," "utilization of health care," and "contraceptive use" we examined the causal paths among the three. This analytical approach is particularly useful for assessing the hypothesized direct and indirect relationships among contraceptive use and the two independent variables "utilization of health care" and "reproductive rights knowledge" as stated by the third hypothesis.

\section{Ethics Consideration}

Ethics clearance (QAU/Soc/2016) was obtained from the Quaid-Azam-University Sociology Departmental Committee Institutional Review Board. Consent was obtained from each participant. All participants are above 18 years of age. The ethical review committee identified the study procedure to cause less than very minimal risk after assessing the proposal document. All participants provided written informed consent, and this study was conducted in accordance with the Declaration of Helsinki with regard to ethical principles for research involving human subjects. Participants were informed that they had the right to withdraw from the study at any time.

\section{Results}

The degree of association between the response variable, "contraceptive use," and each of the independent variables estimated using MCA are represented by eta and beta values (see Table 1.) The eta values are similar to the unadjusted gross association between the outcome variable and independent

Table I MCA Table of the Effects of "Utilization of Health Care"(UHC); "Reproductive Rights Knowledge”; and Control Variables on "Contraceptive Use" Expressed as Deviation from the Grand Mean

\begin{tabular}{|c|c|c|c|c|c|}
\hline \multirow[t]{2}{*}{ Predictor Variables } & \multirow[t]{2}{*}{$\mathbf{N}$} & \multicolumn{2}{|l|}{ Unadjusted Effects } & \multicolumn{2}{|l|}{ Adjusted Effects } \\
\hline & & Contraceptive Use & Eta & Contraceptive Use & Beta \\
\hline Utilization of Health Care & & & 0.609 & & 0.567 \\
\hline $0=$ Low level & 80 & -.244 & & & \\
\hline $\mathrm{I}=$ High level & 80 & 0.244 & & & \\
\hline Reproductive Rights Knowledge & & & 0.345 & & 0.121 \\
\hline $0=$ Low level & 76 & -.143 & & & \\
\hline I=High level & 84 & 0.129 & & & \\
\hline Work status (Workdum) & & & 0.071 & & 0.099 \\
\hline $0=$ Not working & 41 & -.047 & & & \\
\hline I=Working & 119 & 0.016 & & & \\
\hline Family Type (Famtype) & & & 0.046 & & 0.002 \\
\hline $0=$ Joint family & 79 & 0.018 & & & \\
\hline $\mathrm{I}=$ Not joint Family & 81 & -.018 & & & \\
\hline Education status & & & 0.062 & & 0.029 \\
\hline $0=$ Does not hold a graduate degree & 49 & 0.037 & & & \\
\hline I=Holds graduate Degree & 119 & -.016 & & & \\
\hline Model R-Square & & & & & 0.626 \\
\hline
\end{tabular}


variable, and the beta values are adjusted (net effect) for the effects of other variables in the model. The magnitude of the grand mean of "contraceptive use" (0.536) under the impact of "utilization of health care" registered an adjusted mean score of $0.760(0.536+0.224)$, a $40 \%$ increase. Under the influence of "reproductive rights knowledge," the adjusted mean score was $0.581(0.536+0.045)$, recording only a $9 \%$ increase. As suggested by the magnitude of the beta values, the largest effect on "contraceptive use" is from "utilization of health care" and the second largest value is with "reproductive rights knowledge." Though MCA results suggest that both "utilization of health care" and "reproductive rights knowledge" are influential, the significance of their effects can be more directly assessed within multivariate techniques such as logistic regression.

The significance of "utilization of health care" on "contraceptive use" net of the effects of control variables was assessed using logistic regression. The dependent variable, "contraceptive use", and the two independent variables, "utilization of health care" and "reproductive rights knowledge" were dichotomized at their respective medians for the purpose of logistic regression analysis. The odds of being in the high category of "contraceptive use" are presented in Table 2. "Reproductive rights knowledge" was significant only at the $10 \%$ level while all the controls were insignificant. These results from MCA suggest that "utilization of health care" plays a direct and significant role in "contraceptive use".

To further investigate the relationship between "reproductive rights knowledge," "utilization of health care," and "contraceptive use" we examined the causal paths among the three. The correlation (0.358) between "reproductive rights knowledge" and "contraceptive use" is significant at the 0.05 level $\left(\mathrm{R}^{2}=0.358, F(1158)=23.20, \mathrm{p}<0.01\right)$. When "utilization of health care" was introduced in the model as an intervening variable as hypothesized, the effect of "reproductive rights knowledge" on "contraceptive use" became insignificant as seen in Table 3 .

"Reproductive rights knowledge" had a strong and significant net effect on "utilization of health care" as hypothesized. However, the direct and significant effect of 0.358 of "reproductive rights knowledge" on "contraceptive use" became insignificant. Thus, the variable "reproductive rights knowledge" has an indirect effect on "contraceptive use." More specifically, the causal chain among the three variables is "reproductive rights knowledge" - > "utilization of health care"- > "contraceptive use".

\section{Discussion}

Prior to the advent of the reproductive rights approach, family planning was synonymous with fertility control. Two major conferences, the International Conference on Population and Development in 1994 and the Beijing conference that took place a year later, were the beginning of a sea change in family planning ideologies worldwide. Presently, though population control institutions appear to promote the reproductive-rights approach to family planning, their acceptance of this approach remains perfunctory. ${ }^{13}$ Consequently, there have been only very few studies on the effects of reproductive rights on reproductive health outcomes. In the absence

Table 2 Logistic Regression of "Contraceptive Use" on Independent Variables Net of the Effects of Control Variables

\begin{tabular}{|l|l|l|l|l|l|l|}
\hline Variables & Beta (B) & Standard Error & Wald & P value & Odds Ratio & 95\% Cl (Lower, Upper) \\
\hline Utilization of Health Care & 1.876 & 0.389 & 23.267 & 0.000 & 6.526 & $(3.04,13.98)$ \\
\hline Reproductive Rights Knowledge & 0.605 & 0.385 & 2.467 & 0.116 & 1.831 & $(0.86,03.89)$ \\
\hline
\end{tabular}

Notes: Model Chi-Squared $=41.96 . \mathrm{p}<0.05$. Nagelkerke R Square $=0.31 . \mathrm{N}=160$.

Table 3 Path Model: Net Effects Controlling for Workdum, Famtype and Edudum

\begin{tabular}{|l|l|l|l|l|l|}
\hline \multicolumn{2}{|l|}{ Causal Effects Among Variables (Label) } & Estimates & Std. Error & Z-Value & P-value \\
\hline Reproductive rights knowledge (RRK) & $\rightarrow$ Contraceptive use (CU) & 0.065 & 0.059 & 0.969 & 0.333 \\
\hline Utilization of health care (UHC) & $\rightarrow$ Contraceptive use (CU) & 0.630 & 0.60 & 9.412 & 0.001 \\
\hline Reproductive rights knowledge(RRK) & Utilization of health care (UHC) & 0.468 & 0.069 & 6.687 & 0.001 \\
\hline CU - Unexplained variance & 0.087 & 0.010 & 8.916 & 0.001 \\
\hline
\end{tabular}


of empirical studies on the relationship between reproductive rights knowledge and contraceptive use, the hypothesized positive association between the two remains, to an extent conjectural in social scientific and policy circles. Programs to impart values about reproductive rights among women are few and far between. To address the dearth of studies on the effect of reproductive rights knowledge on contraceptive use, this study was undertaken using a purposive sample of Pakistani women with a graduate degree in the reproductive age group 18-45 years.

Adhering to an old dictum that knowledge leads to practice, we hypothesized that reproductive rights knowledge will likely have a direct effect on contraceptive use. In addition, women's ongoing demands for reproductive health care and their reproductive well-being are heavily dependent on the availability and accessibility of health care systems. ${ }^{34}$ Subsequently, reproductive rights knowledge is likely to be correlated with utilization of health care. We hypothesized that both utilization of health care and reproductive rights knowledge are likely to have significant effects on contraceptive use.

Our results suggest that reproductive rights knowledge has no direct effect on contraceptive use. Furthermore, the level of utilization of the health care system plays a significant intervening role between reproductive rights knowledge and contraceptive use. Building a viable and accessible health care system that continuously improves the uptake of women who want to utilize health care is essential to improve contraceptive use. Our results lend support to this line of argument.

Our results may be enveloped within the theoretical frame of contraceptive autonomy offered by Senderowicz. ${ }^{5}$ The concept of contraceptive autonomy locates family planning within the context of women wanting or not wanting family planning. This capacity to decide for themselves what is in their best interest in terms of reproductive goals and to achieve the capability to achieve those reproductive goals are central to women's reproductive rights. That approach surpasses political agendas, which use family planning to achieve population goals under the broad agenda of "populationism." 35

Women's ability to access and utilize health care services for reproductive health problems as and when they arise fosters confidence in the system and incentivizes contraceptive use. In the absence of a viable system of health care delivery services, women's ability to plan for, and utilize preventive care such as contraceptive use may be limited, as contraceptive use involves preplanning and the ability to visualize a family size she would likely enjoy. Merely improving reproductive rights knowledge may not improve contraceptive use. These results underscore the importance of linking improvements in quality of care $^{36},{ }^{37}$ accessibility and availability of health care systems with family planning programs.

\section{Conclusion}

Infusion of rights language into policies has actively influenced legislatures and policymaking bodies in developing countries. This influence resulted in the formulation of laws and policies that protect women's rights. The beneficiaries of such rights have been mostly only a small group of women who are aware of their rights because of deep social inequalities in the society which marginalizes a large proportion of women. ${ }^{38}$ In this study, we have produced empirical evidence indicating that widespread reproductive rights may be associated with increases in the utilization of health care facilities and that the presence of a highly utilized health care system results in an increase in contraceptive use. Similar findings around the presence of an accessible family planning programs promoting rights and behavioral modifications necessary for AIDS prevention have been reported from developing countries such as Zambia. ${ }^{39}$ At a broad level, our results suggest the importance of the synergy that exists between improved health care systems, reproductive rights knowledge levels, and contraceptive use in developing countries such as Pakistan.

Our study has limitations. First, the purposive sample used in this study limits us from generalizing our results. Second, at a theoretical level, we have not made the linkage between the spread of reproductive rights values and other equally noteworthy values such as gender equality and egalitarianism. It is worthwhile to unravel the web of correlations among ongoing value changes and reproductive rights knowledge among women in developing countries. Such studies may offer a window into the strategies for improving reproductive rights knowledge among Pakistani women. Finally, our attempts to contribute to Sanderowicz's ${ }^{5}$ concept of "contraceptive autonomy" remains modest, suggesting the need for a number of studies on the measurement as well as theoretical aspects of contraceptive use and autonomy. 


\section{Abbreviations}

BPLR, Bootstrapped Parametric Likelihood Ratio test; CEDAW, the Convention on the Elimination of All Forms of Discrimination against Women; MCA, multiple classification analysis; VLMR, Vuong-Lo-Mendell-Rubin test.

\section{Ethics Approval and Consent to Participate}

Ethics clearance (QAU/Soc/2016) was obtained from the Quaid-Azam-University Sociology Departmental Committee Institutional Review Board. Consent was obtained from each participant.

\section{Funding}

There is no funding to report.

\section{Disclosure}

The authors report no conflicts of interest in this work.

\section{References}

1. Miller G, Babiarz KS. Family planning program effects: evidence from microdata. Popul Dev Rev. 2016;2(1):7-26.

2. Khumayah S, Siswoyo M. Male family planning program as an effort to suppress population growth in Indonesia. AJSSH. 2019;9(2):91-97.

3. Hartmann B. Reproductive Rights and Wrongs: The Global Politics of Population Control. Boston: South End Press; 1995.

4. Day CA, White B, Reid SE, Fowler M, Black KI. Integration of a contraception clinic into an opioid treatment setting to improve contraception knowledge, accessibility and uptake: a pilot study. Aust N Z J Public Health. 2020;44(5):360-362. doi:10.1111/17536405.13025

5. Senderowicz L. Contraceptive autonomy: conceptions and measurement of a novel family planning indicator. Stud Fam Plan. 2020;51 (2):161-176. doi:10.1111/sifp.12114

6. World Health Organization. The World Health Report: 1999: Making a Difference. Geneva: World Health Organization; 1999.

7. Peters JS, Wolper A, eds. Women's Rights, Human Rights: International Feminist Perspectives. Abington: Routledge; 2018.

8. Combellick-Bidney S. Reproductive rights as human rights: stories from advocates in Brazil, India and South Africa. Int J Hum Right. 2017;21(7):800-822. doi:10.1080/13642987.2016.1276446

9. Valente PK. Zika and reproductive rights in Brazil: challenge to the right to health. Am J Public Health. 2017;107(9):1376-1380. doi:10.2105/AJPH.2017.303924

10. Jarvis K, Farrell A, Richter S, Lukewich J. Determinants of accessibility to primary sexual reproductive health care among vulnerable women in Canada: a scoping review protocol. JBI Evid Synth. 2020;18(9):2065-2074. doi:10.11124/JBISRIR-D-1900262

11. Agha S, Williams E. Does the antenatal care visit represent a missed opportunity for increasing contraceptive use in Pakistan? An analysis of household survey data from Sindh province. Health Policy Plan. 2016;31(3):325-331. doi:10.1093/heapol/czv065

12. Rosenstock IM. The health belief model and preventive health behavior. Health Educ Monogr. 1974;2(4):354-386. doi:10.1177/ 109019817400200405
13. Bayley J, Brown K, Wallace L. Teenagers and emergency contraception in the UK: a focus group study of salient beliefs using concepts from the theory of planned behaviour. Eur J Contracept Reprod Health Care. 2009;14(3):196-206. doi:10.1080/13625180902741444

14. Luker K. Taking Chances: Abortion and the Decision Not to Contracept. Univ of California Press; 1975.

15. Crosbie PV, Bitte D. A test of luker's theory of contraceptive risktaking. Stud Fam Plan. 1982;13(3):67-78. doi:10.2307/1966179

16. Pillai VK, Conaway M. Immunisation coverage in Lusaka, Zambia; implications of the social setting. J Biosoc Sci. 1992;24(2):201-210. doi: $10.1017 / \mathrm{S} 0021932000019738$

17. Sen A. Development as Freedom. New York: Knopf; 1999.

18. Fukuda-Parr S, Cid-Martinez I. Capability approach and human development. In: Nissake $\mathrm{M}$, Ocampo JA, editors. The Palgrave Handbook of Development Economics. Cham: Palgrave Macmillan; 2019:441-468.

19. Punjani NS. Determinants associated with unmet need for family planning in Pakistan. J Womens Health Issues Care. 2018;7:1. doi:10.4172/2325-9795.1000306

20. Agha S. Intentions to use contraceptives in Pakistan: implications for behavior change campaigns. BMC Public Health. 2010;10(1):450. doi:10.1186/1471-2458-10-450

21. Tadesse T, Dangisso MH, Abebo TA. Sexual and reproductive health rights knowledge and reproductive health services utilization among rural reproductive age women in Aleta Wondo District, Sidama zone, Ethiopia: community based cross-sectional study. BMC Int Health Hum Rights. 2020;20(1):1-9. doi:10.1186/s12914-020-00223-1

22. Manning WD, Longmore MA, Giordano PC. The relationship context of contraceptive use at first intercourse. Fam Plan Perspect. 2000;1:104-110. doi:10.2307/2648158

23. Brückner H, Martin A, Bearman PS. Ambivalence and pregnancy: adolescents' attitudes, contraceptive use and pregnancy. Perspect Sex Reprod Health. 2004;36(6):248-257. doi:10.1363/3624804

24. Alabi O, Odimegwu CO, De-wet N, Akinyemi JO. Does female autonomy affect contraceptive use among women in northern Nigeria? Afr J Reprod Health. 2019;23(2):92-100. doi:10.29063/ajrh2019/v23i2.9

25. Koc I. Determinants of contraceptive use and method choice in Turkey. $J$ Biosoc Sci. 2000;32(3):329-342. doi:10.1017/ S0021932000003291

26. Kamal SM, Aynul Islam M. Contraceptive use: socioeconomic correlates and method choices in rural Bangladesh. Asia Pac J Public Health. 2010;22(4):436-450. doi:10.1177/1010539510370780

27. Nyarko SH. Prevalence and correlates of contraceptive use among female adolescents in Ghana. BMC Women's Health. 2015;15(1):60. doi:10.1186/s12905-015-0221-2

28. Al Riyami A, Afifi M, Mabry RM. Women's autonomy, education and employment in Oman and their influence on contraceptive use. Reprod Health Matters. 2004;12(23):144-154. doi:10.1016/S09688080(04)23113-5

29. Gordon C, Sabates R, Bond R, Wubshet T. Women's education and modern contraceptive use in Ethiopia. Int J Educ. 2011;3(1):1.

30. Gouher A Knowledge and practice of reproductive rights among educated married females in Ismalabad, Pakistan [Thesis]. Islamabad, Pakistan: Quaid-I-Azam University. 2016.

31. Pampel F. Cohort changes in the socio-demographic determinants of gender egalitarianism. Soc Forces. 2011;89(3):961-982. doi:10.1353/ sof.2011.0011

32. Kurzman C, Dong W, Gorman B, Hwang K, Ryberg R, Zaidi B. Women's assessments of gender equality. Socius. 2019;5:2378023119872387. doi:10.1177/2378023119872387

33. Asparouhov T, Muthén B. Using Mplus TECH11 and TECH14 to test the number of latent classes. Mplus Web Notes. 2012;14:22.

34. Bhatia R, Sasser JS, Ojeda D, Hendrixson A, Nadimpally S, Foley EE. A feminist exploration of 'populationism': engaging contemporary forms of population control. Gend Place Cult. 2020;27 (3):333-350. doi:10.1080/0966369X.2018.1553859 
35. Okonofua F, Ntoimo L, Ogungbangbe J, Anjorin S, Imongan W, Yaya S. Predictors of women's utilization of primary health care for skilled pregnancy care in rural Nigeria. BMC Pregnancy and Childb. 2018;18(1):1-5. doi:10.1186/s12884-018-1730-4

36. Shaikh BT, Hatcher J. Health seeking behaviour and health service utilization in Pakistan: challenging the policy makers. J Public Health. 2005;27(1):49-54. doi:10.1093/pubmed/fdh207

37. Bruce J. Fundamental elements of the quality of care: a simple framework. Stud Fam Plann. 1990;21(2):61-91. doi:10.2307/ 1966669
38. Sen G, Grown C. Development, Crises and Alternative Visions: Third World Women's Perspectives. New York: Monthly Review Press; 1988.

39. Pillai VK, Sunil TS, Gupta R. AIDS prevention in Zambia: implications for social services. World Dev. 2003;31(1):149-161. doi:10.1016/S0305-750X(02)00179-1

\section{Publish your work in this journal}

Open Access Journal of Contraception is an international, peerreviewed, open access, online journal, publishing original research, reports, reviews and commentaries on all areas of contraception. In addition to clinical research, demographics and health-related aspects, the journal welcomes new findings in animal and preclinical studies relating to understanding the biological mechanisms and practical development of new contraceptive agents. The manuscript management system is completely online and includes a very quick and fair peer-review system. Visit http://www.dovepress.com/testimonials. php to read real quotes from published authors. 